\title{
A Thermochemical and Theoretical Study of the Phenylpyridine Isomers
}

\author{
M. A. V. Ribeiro da Silva,* M. A. R. Matos, and C. A. Rio \\ Centro de Investigação em Química, Departamento de Química, Faculdade de Ciências da Universidade do \\ Porto, Rua do Campo Alegre, 687, P-4169-007 Porto, Portugal
}

\author{
V. M. F. Morais \\ Instituto de Ciências Biomédicas Abel Salazar, Universidade do Porto, P-4099-003 Porto, Portugal \\ J. Wang, G. Nichols, and J. S. Chickos \\ Department of Chemistry, University of Missouri-St. Louis, St. Louis, Missouri 63121
}

Received: November 8, 1999

\begin{abstract}
The standard $\left(p^{\circ}=0.1 \mathrm{MPa}\right)$ molar enthalpies of formation for 2-, 3-, and 4-phenylpyridine in the gas phase were derived from the standard molar enthalpies of combustion, in oxygen, at $298.15 \mathrm{~K}$, measured by static bomb combustion calorimetry. The standard molar enthalpies of vaporization for 2-, 3-, and 4-phenylpyridine at $T=298.15 \mathrm{~K}$ were measured by correlation-gas chromatography. The enthalpy of sublimation of 4-phenylpyridine was obtained as a weighted mean of the value derived from the vaporization and fusion enthalpy values and the value measured directly by Calvet microcalorimetry. The following enthalpies of formation were then derived: 2-phenylpyridine, $g=228.3 \pm 5.8 \mathrm{~kJ} \cdot \mathrm{mol}^{-1}$; 3-phenylpyridine, $g=240.9 \pm$ $5.5 \mathrm{~kJ} \cdot \mathrm{mol}^{-1}$; 4-phenylpyridine, $g=240.0 \pm 3.3 \mathrm{~kJ} \cdot \mathrm{mol}^{-1}$. The most stable geometries of all phenylpyridine isomers were obtained using both restricted Hartree-Fock (RHF) and density functional theory (DFT/B3LYP) methods. The resulting geometries were then used to obtain estimates of enthalpies of formation of the three isomers of phenylpyridine, which are in good agreement with the experimental values. A theoretical interpretation of the effect of the phenyl ring has on the relative stabilities of the three molecules is presented.
\end{abstract}

\section{Introduction}

The study of the thermochemical parameters of aromatic heterocycles, namely pyridines, bipyridines, quinolines, diazines, and benzodiazines, has been a continuing interest in our laboratory. ${ }^{1}$ It is our aim to enlarge the thermochemical data base of these substances in order to gain an understanding of the energetic effects of substitutions in the ring and their dependence both on the number of nitrogen atoms and their relative positions to the heteroatom.

In the present work, we report the standard molar enthalpies of formation of the three isomers of phenylpyridine, at $T=$ 298.15 K, obtained from measurements of combustion energies using a static bomb combustion calorimeter, and values for the enthalpies of vaporization of the ortho and meta compounds measured by correlation-gas chromatography, and the enthalpy of sublimation of the para isomer determined both by Calvet microcalorimetry and combined correlation-gas chromatography-differential scanning calorimetry. Ab initio calculations were performed in order to obtain the most stable geometries for these molecules. The good agreement obtained between the experimentally and theoretically derived enthalpies of formation of the phenylpyridines provided us with a theoretical interpretation of the effect the position of the phenyl ring has on the relative stabilities of the three molecules.

\section{Experimental Section}

Materials. The phenylpyridines were obtained commercially from Aldrich Chemical Co., and they were purified by repeated

\footnotetext{
* Corresponding author. E-mail: risilva@fc.up.pt.
}

vacuum distillation or sublimation until the combustion results were consistent and the carbon dioxide recovery ratios were satisfactory. The average ratios, together with the standard deviation of the mean, of the mass of carbon dioxide recovered to that calculated from the mass of sample were as follows: 2-PhPy, $1.0007 \pm 0.0002$; 3-PhPy, $0.9997 \pm 0.0005$; 4- PhPy, $1.0001 \pm 0.0005$. The densities of the samples were as follows: 2-PhPy, $\rho=1.08 \mathrm{~g} \cdot \mathrm{cm}^{-3.2}$;-PhPy, $\rho=1.08 \mathrm{~g} \cdot \mathrm{cm}^{-3}$; 4-PhPy, $\rho=1.14 \mathrm{~g} \cdot \mathrm{cm}^{-3}$.

Combustion Calorimetry. The combustion experiments were performed in Porto with a static bomb calorimeter. The apparatus and technique have been described. ${ }^{3,4}$ Benzoic acid (Bureau of Analysed Samples, Thermochemical Standard, BCS-CRM-190 p) was used for calibration of the bomb. Its massic energy of combustion is $\Delta_{\mathrm{c}} u=-26432.3 \pm 3.8 \mathrm{~J} \cdot \mathrm{g}^{-1}$, under certificate conditions. The calibration results were corrected to give the energy equivalent $\epsilon_{\mathrm{cal}}$ corresponding to the average mass of water added to the calorimeter: $3119.6 \mathrm{~g}$. In the experiments of 2- and 3-phenylpyridine, the bomb used was a Parr model $1105, \epsilon_{\mathrm{cal}}=15911.2 \pm 1.5 \mathrm{~J} \cdot \mathrm{K}^{-1}$. For 4-phenylpyridine we used a Parr model 1108, $\epsilon_{\text {cal }}=16013.9 \pm 1.7 \mathrm{~J} \cdot \mathrm{K}^{-1}$. The uncertainties quoted are the standard deviations of the mean unless otherwise noted. For all experiments, ignition was made at $T=298.150 \pm 0.001 \mathrm{~K}$. Combustion experiments were made in oxygen at $p=3.04 \mathrm{MPa}$, with $1.00 \mathrm{~cm}^{3}$ of water added to the bomb. The electrical energy for ignition $\Delta U($ ign $)$ was determined from the change in potential difference across a capacitor when discharged through the platinum ignition wire. For the cotton thread fuse, the empirical formula $\mathrm{CH}_{1.686} \mathrm{O}_{0.843}$, 
$\Delta_{\mathrm{c}} u^{\circ}=-16250 \mathrm{~J} \cdot \mathrm{g}^{-1}$ was used. ${ }^{5}$ The corrections for nitric acid formation $\Delta U\left(\mathrm{HNO}_{3}\right)$ were based on $-59.7 \mathrm{~kJ} \cdot \mathrm{mol}^{-1}$ for the molar energy of formation of $0.1 \mathrm{~mol} \cdot \mathrm{dm}^{-3} \mathrm{HNO}_{3}(\mathrm{aq})$ from $\mathrm{N}_{2}, \mathrm{O}_{2}$, and $\mathrm{H}_{2} \mathrm{O}(\mathrm{l}){ }^{6}$. Sealed Melinex bags were used in combustion of the liquid 2- and 3-PhPy, using the technique described by Skinner and Snelson, ${ }^{7}$ who determined the specific energy of combustion of dry Melinex as $\Delta_{\mathrm{c}} u^{\circ}=-22902 \pm 5$ $\mathrm{J} \cdot \mathrm{g}^{-1} .^{7}$ This value was confirmed in our laboratory. The mass of Melinex used in each experiment was corrected for the mass fraction of water $(0.0032) .{ }^{7}$ Hexadecane was used as an auxiliary in the combustion experiments of 4-phenylpyridine to make them complete, $\Delta_{\mathrm{c}} u^{\circ}=-47076.7 \pm 3.3 \mathrm{~J} \cdot \mathrm{g}^{-1} \cdot$ The amount of substance $m$ (compound) used in each experiment was determined from the total mass of carbon dioxide $m\left(\mathrm{CO}_{2}\right.$, total $)$ produced after allowance for that formed from the cotton thread fuse, hexadecane, and Melinex and that lost due to carbon formation. Corrections for carbon formation were based on $\Delta_{\mathrm{c}} u^{\circ}$ $=33 \mathrm{~kJ} \mathrm{~mol}^{-1} \cdot{ }^{8} \mathrm{An}$ estimated pressure coefficient of specific energy, $(\partial u / \partial p)_{\mathrm{T}}=-0.2 \mathrm{~J} \cdot \mathrm{g}^{-1} \cdot \mathrm{MPa}^{-1}$ at $T=298.15 \mathrm{~K}$, a typical value for most organic compounds, was assumed. For each compound, the massic energy of combustion, $\Delta_{\mathrm{c}} u^{\circ}$, was calculated by the procedure given by Hubbard et al. ${ }^{8}$ The molar masses used for the elements were those recommended by the IUPAC comission. ${ }^{9}$

Enthalpies of Vaporization and Sublimation. The vaporization enthalpies of 2-, 3-, and 4-phenylpyridine at $298.15 \mathrm{~K}$ were measured in St. Louis by correlation gas chromatography. Separation of two of the three isomers was not achieved by the gas chromatographic column used and therefore all three isomers were analyzed independently. The 2- and 4-isomers were also analyzed simultaneously in a single mixture. The values obtained were not dependent on composition of the mixture within experimental error. The values reported are averaged results from a series of mixtures. The compounds used as standards and their vaporization enthalpies include the following: biphenyl $65.6 \mathrm{~kJ} \cdot \mathrm{mol}^{-1}(298.15 \mathrm{~K}) ;{ }^{10}$ naphthalene $55.7 \mathrm{~kJ} \cdot \mathrm{mol}^{-1}(298.15$ $\mathrm{K}) ;{ }^{10}$ anthracene $77.9 \mathrm{~kJ} \cdot \mathrm{mol}^{-1}(298.15 \mathrm{~K}) ;{ }^{10}$ isoquinoline 50.8 $\mathrm{kJ} \cdot \mathrm{mol}^{-1}(457.4 \mathrm{~K}),{ }^{10} 55.7 \mathrm{~kJ} \cdot \mathrm{mol}^{-1}(298.15 \mathrm{~K}) ;{ }^{11}$ quinoline $48.9 \mathrm{~kJ} \cdot \mathrm{mol}^{-1}(455 \mathrm{~K}) ;^{12} 58.9 \mathrm{~kJ} \cdot \mathrm{mol}^{-1}(298.15 \mathrm{~K}){ }^{11}{ }^{11} 2,3-$ lutidine $41.14 \mathrm{~kJ} \cdot \mathrm{mol}^{-1}(432.0 \mathrm{~K}) ;{ }^{13} 49.0 \mathrm{~kJ} \cdot \mathrm{mol}^{-1}(298.15 \mathrm{~K}) ;{ }^{11}$ 2,6-dimethylquinoline $55.6 \mathrm{~kJ} \cdot \mathrm{mol}^{-1}(478 \mathrm{~K}) ;{ }^{14} 69.7 \mathrm{~kJ} \cdot \mathrm{mol}^{-1}$ $(298.15 \mathrm{~K}) ; 11$ 1-methylnaphthalene $52.0 \mathrm{~kJ} \cdot \mathrm{mol}^{-1}(434 \mathrm{~K}) ;^{15}$ $61.7 \mathrm{~kJ} \cdot \mathrm{mol}^{-1}(298.15 \mathrm{~K}) ; ;^{11}$ acridine $66.2 \mathrm{~kJ} \cdot \mathrm{mol}^{-1}(417 \mathrm{~K}) ; 16$ $76.1 \mathrm{~kJ} \cdot \mathrm{mol}^{-1}(298.15 \mathrm{~K}){ }^{11}$ Vaporization enthalpies measured at temperatures other than $298.15 \mathrm{~K}$ were corrected to this temperature. The solvent used was methylene chloride which was not retained by the column at the temperatures of the experiments (435-490 K) and was used to correct for the dead volume of the column. The adjusted retention time of each component in the mixture, which is inversely proportional to the vapor pressure of the solute, was plotted on a logarithmic scale against the reciprocal absolute temperature over a temperature range of approximately $35 \mathrm{~K}$ over $5 \mathrm{~K}$ intervals. The plot resulted in straight lines characterized by correlation coefficients $\left(r^{2}\right)$ that exceeded 0.999 in all cases. The enthalpy of transfer from solution to the vapor for each of the components of the mixture, obtained by multiplying the magnitude of the slope of the line by the gas constant, $R$, was correlated with its vaporization enthalpy at $T=298.15 \mathrm{~K}$. Good linear correlations were observed with correlation coefficients $\left(r^{2}\right)$ that exceeded 0.977. This demonstrates that enthalpies of transfer and vaporization enthalpies of hydrocarbons and tertiary amines correlate with each other in a linear fashion. The vaporization enthalpy for each of the phenylpyridines was obtained from the correla-
TABLE 1: Typical Combustion Experiments at $T=298.15 \mathrm{~K}$

\begin{tabular}{llll}
\hline & \multicolumn{1}{r}{$2-\mathrm{PhPy}$} & \multicolumn{1}{r}{$3-\mathrm{PhPy}$} & \multicolumn{1}{c}{$4-\mathrm{PhPy}$} \\
\hline$m\left(\mathrm{CO}_{2}\right.$, total $) / \mathrm{g}$ & 1.97900 & 1.15770 & 2.03088 \\
$m^{\prime}($ compound $) / \mathrm{g}$ & 0.60311 & 0.33932 & 0.44862 \\
$m^{\prime \prime}($ fuse $) / \mathrm{g}$ & 0.00360 & 0.00450 & 0.00363 \\
$m^{\prime \prime \prime}($ Melinex $)$ & 0.04013 & 0.04050 & \\
$m^{\prime \prime \prime \prime \prime}($ hexadecane $)$ & & & 0.20119 \\
$\Delta T_{\mathrm{ad}} / \mathrm{K}$ & 1.47168 & 0.85803 & 1.63767 \\
$\epsilon_{\mathrm{cal}} /\left(\mathrm{J} \cdot \mathrm{K}^{-1}\right)$ & $15911.2 \pm 1.5$ & $15911.2 \pm 1.5$ & $16013.9 \pm 1.7$ \\
$\epsilon_{\mathrm{f}} /\left(\mathrm{J} \cdot \mathrm{K}^{-1}\right)$ & 16.02 & 15.33 & 16.26 \\
$\Delta m\left(\mathrm{H}_{2} \mathrm{O}\right) / \mathrm{g}$ & 0.1 & 0.0 & 0.0 \\
$-\Delta U(\mathrm{IBP}) / \mathrm{J}$ & 23440.39 & 13665.44 & 26250.92 \\
$-\Delta U($ fuse)/J & 58.46 & 73.08 & 58.95 \\
$-\Delta U(\mathrm{Melinex}) / \mathrm{J}$ & 919.04 & 919.96 & \\
$-\Delta U($ hexadecane $) / \mathrm{J}$ & & & 9471.36 \\
$\left.-\Delta U(\mathrm{HNO})_{3}\right) / \mathrm{J}$ & 20.18 & 19.52 & 29.13 \\
$-\Delta U($ carbon $) / \mathrm{J}$ & 0.00 & 0.00 & 0.00 \\
$\Delta U($ ign $) / \mathrm{J}$ & 1.23 & 1.16 & 1.19 \\
$-\Delta U_{\Sigma} / \mathrm{J}$ & 14.55 & 8.14 & 12.79 \\
$-\Delta \Delta_{\mathrm{c}} \boldsymbol{H}^{\prime} /\left(\mathrm{J} \cdot \mathrm{J}^{-1}\right)$ & 37185.47 & 37261.52 & 37177.77
\end{tabular}

tion equations and their enthalpies of transfer. With the exception of 3-phenylpyridine, the error associated with each vaporization enthalpy was derived from the standard deviation associated with the results obtained using different mixtures.

4-Phenylpyridine is a solid at room temperature. The fusion enthalpy of 4-phenylpyridine was measured on a Perkin-Elmer DSC-7. A fusion enthalpy of $19.95 \pm 0.04 \mathrm{~kJ} \cdot \mathrm{mol}^{-1}$, the mean of four determinations, was obtained at $T=346.9 \mathrm{~K}$. The sublimation enthalpy of 4-phenylpyridine was obtained by combining the vaporization enthalpy, $68.4 \pm 3.5 \mathrm{~kJ} \cdot \mathrm{mol}^{-1}$ (298.15 K), with the fusion enthalpy adjusted to $T=298.15 \mathrm{~K}$ according to the protocol described recently. ${ }^{11}$ Heat capacities used for the temperature corrections were estimated. ${ }^{17}$ The enthalpy of sublimation of 4-phenylpyridine was also measured in Porto by using the "vacuum sublimation" drop microcalorimetric method. ${ }^{18}$ Samples, about 3-5 mg, contained in thin glass capillary tubes sealed at one end, were dropped, at room temperature, into the hot reaction vessel, in a high-temperature Calvet microcalorimeter held at $T=367 \mathrm{~K}$, and then removed from the hot zone by vacuum sublimation. The observed enthalpy of sublimation was corrected to $T=298.15 \mathrm{~K}$ by using the value of $\Delta_{298.15 \mathrm{~K}}^{T} H_{\mathrm{m}}^{\circ}(\mathrm{g})$ estimated by a group method with values from Stull et al. ${ }^{19}$ The microcalorimeter was calibrated in situ for these measurements by using the reported enthalpy of sublimation of naphthalene. ${ }^{20}$

\section{Experimental Results}

Results for a typical combustion experiment of each compound are given in Table 1 , where $\Delta m\left(\mathrm{H}_{2} \mathrm{O}\right)$ is the deviation of the mass of water added to the calorimeter from $3119.6 \mathrm{~g}$, and $\Delta U_{\Sigma}$ is the correction to the standard state. The remaining quantities are as previously described. ${ }^{6}$ As samples were ignited at $T=298.15 \mathrm{~K}$

$$
\begin{aligned}
\Delta U(\mathrm{IBP})= & \\
& -\left\{\epsilon_{\mathrm{cal}}+\Delta m\left(\mathrm{H}_{2} \mathrm{O}\right) c_{p}\left(\mathrm{H}_{2} \mathrm{O}, \mathrm{l}\right)+\epsilon_{\mathrm{f}}\right\} \Delta T_{\mathrm{ad}}+\Delta U_{\mathrm{ign}}
\end{aligned}
$$

where $\Delta U(\mathrm{IBP})$ is the energy associated with the isothermal bomb process, $\epsilon_{\mathrm{f}}$ is the energy of the bomb contents after ignition, and $\Delta T_{\mathrm{ad}}$ is the adiabatic temperature rise. The individual results of all combustion experiments, together with the mean value and standard deviation, are given for each compound in Table 2. Table 3 lists the derived standard $\left(p^{\circ}=\right.$ $0.1 \mathrm{MPa}$ ) molar energies and enthalpies of combustion, $\Delta_{\mathrm{c}} U_{\mathrm{m}}^{\circ}$ (cr,l) and $\Delta_{\mathrm{c}} H_{\mathrm{m}}^{\circ}(\mathrm{cr}, 1)$, and the standard molar enthalpies of 
TABLE 2: Individual Values of the Massic Energy of Combustion, $\Delta_{\mathrm{c}} u^{\circ}$, of the Phenylpyridines, at $T=298.15 \mathrm{~K}$

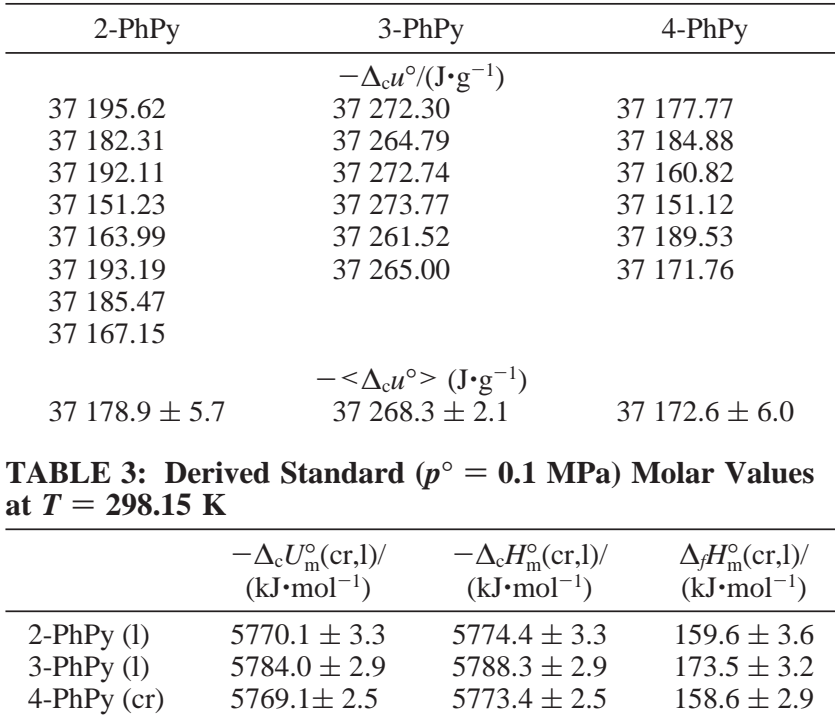

TABLE 4: Derived Standard $\left(p^{\circ}=0.1 \mathrm{MPa}\right)$ Molar Values at $T=298.15 \mathrm{~K}$

\begin{tabular}{lccc}
\hline & $\begin{array}{c}\Delta_{\mathrm{f}} H_{\mathrm{m}}^{\circ}(\mathrm{cr}, 1) / \\
\left(\mathrm{kJ} \cdot \mathrm{mol}^{-1}\right)\end{array}$ & $\begin{array}{c}\Delta_{\mathrm{cr}, 1}^{\mathrm{g}} H_{\mathrm{m}}^{\circ} / \\
\left(\mathrm{kJ} \cdot \mathrm{mol}^{-1}\right)\end{array}$ & $\begin{array}{c}-\Delta_{\mathrm{f}} H_{\mathrm{m}}^{\circ}(\mathrm{g}) / \\
\left(\mathrm{kJ} \cdot \mathrm{mol}^{-1}\right)\end{array}$ \\
\hline 2-PhPy (1) & $159.6 \pm 3.6$ & $68.7 \pm 4.6$ & $228.3 \pm 5.8$ \\
3-PhPy (1) & $173.5 \pm 3.2$ & $67.4 \pm 4.5$ & $240.9 \pm 5.5$ \\
4-PhPy (cr) & $158.6 \pm 2.9$ & $81.4 \pm 1.6^{a}$ & $240.0 \pm 3.3$
\end{tabular}

${ }^{a}$ This value is the weighted mean of the experimental values determined by Calvet microcalorimetry, $80.2 \pm 1.8 \mathrm{~kJ} \cdot \mathrm{mol}^{-1}$, and by chromatography, $86.1 \pm 3.5 \mathrm{~kJ} \cdot \mathrm{mol}^{-1}$

formation for the compounds in the condensed phase, $\Delta_{\mathrm{f}} H_{\mathrm{m}}^{\circ}$ (cr,1), at $T=298.15 \mathrm{~K}$. In accordance with normal thermochemical practice, the uncertainties assigned to the standard molar enthalpies of combustion are, in each case, twice the overall standard deviation of the mean and include the uncertainities in calibration ${ }^{21}$ and in the values of the auxiliary quantities. To derive $\Delta_{\mathrm{f}} H_{\mathrm{m}}^{\circ}(\mathrm{cr}, 1)$ from $\Delta_{\mathrm{c}} H_{\mathrm{m}}^{\circ}(\mathrm{cr}, 1)$ the standard molar enthalpies of formation of $\mathrm{H}_{2} \mathrm{O}(\mathrm{l})$ and $\mathrm{CO}_{2}(\mathrm{~g})$, at $T$ $=298.15 \mathrm{~K},-285.830 \pm 0.042^{22}$ and $-393.51 \pm 0.13$ $\mathrm{kJ} \cdot \mathrm{mol}^{-1}, 22$ respectively, were used.

Measurements of the enthalpies of sublimation and of vaporization $\Delta_{\mathrm{cr}, \mathrm{l}}^{\mathrm{g}} H_{\mathrm{m}}^{\circ}$ are given in Table 4 with uncertainties of twice the standard deviation of the mean. The error associated with the vaporization enthalpy of 3-phenylpyridine, which was analyzed in only one mixture, was derived from the standard error associated with the slope of the correlation equation. The uncertainty represents two standard deviations. The value for the standard molar enthalpy of sublimation of 4-phenylpyridine is the weighted mean of the experimental values determined by Calvet microcalorimetry $80.2 \pm 1.8 \mathrm{~kJ} \cdot \mathrm{mol}^{-1}$ and by chromatography $86.1 \pm 3.5 \mathrm{~kJ} \cdot \mathrm{mol}^{-1}$. The derived enthalpies of formation, in both the condensed and gaseous phases, for all the compounds are also summarized in this table.

\section{Ab Initio Calculations}

The equilibrium geometries of all phenylpyridine isomers have been obtained through full geometry optimization within the framework of two different theoretical approaches: restricted Hartree-Fock (RHF) theory and density functional theory (DFT). For both sets of calculations the molecular wave functions were represented in terms of the Pople split-valence plus polarization $6-31 \mathrm{G}^{*}$ basis set. ${ }^{23}$ In addition, in the DFT
TABLE 5: Calculated Geometries of the Phenylpyridines (Bond Lengths in A; Angles in deg)

\begin{tabular}{|c|c|c|c|c|c|c|}
\hline & \multicolumn{2}{|c|}{ 2-PhPy } & \multicolumn{2}{|c|}{ 3-PhPy } & \multicolumn{2}{|c|}{ 4-PhPy } \\
\hline & RHF & DFT & RHF & DFT & RHF & DFT \\
\hline $1-2$ & 1.326 & 1.348 & 1.393 & 1.407 & 1.391 & 1.403 \\
\hline $2-3$ & 1.319 & 1.335 & 1.319 & 1.336 & 1.383 & 1.394 \\
\hline $3-4$ & 1.383 & 1.395 & 1.320 & 1.339 & 1.321 & 1.339 \\
\hline $4-5$ & 1.384 & 1.394 & 1.384 & 1.395 & 1.321 & 1.339 \\
\hline $5-6$ & 1.381 & 1.391 & 1.382 & 1.392 & 1.383 & 1.393 \\
\hline $6-1$ & 1.394 & 1.405 & 1.390 & 1.402 & 1.391 & 1.403 \\
\hline $1-7$ & 1.491 & 1.488 & 1.489 & 1.483 & 1.489 & 1.484 \\
\hline $7-8$ & 1.392 & 1.405 & 1.393 & 1.405 & 1.392 & 1.405 \\
\hline $8-9$ & 1.385 & 1.394 & 1.384 & 1.394 & 1.384 & 1.394 \\
\hline $9-10$ & 1.384 & 1.396 & 1.385 & 1.396 & 1.385 & 1.396 \\
\hline $10-11$ & 1.387 & 1.397 & 1.385 & 1.396 & 1.385 & 1.396 \\
\hline $11-12$ & 1.383 & 1.393 & 1.385 & 1.394 & 1.384 & 1.394 \\
\hline $12-7$ & 1.393 & 1.405 & 1.393 & 1.393 & 1.392 & 1.405 \\
\hline $1-2-3$ & 119.1 & 118.6 & 124.3 & 124.6 & 119.1 & 119.5 \\
\hline $2-3-4$ & 123.7 & 123.9 & 118.0 & 117.4 & 123.9 & 124.1 \\
\hline $3-4-5$ & 117.5 & 117.7 & 123.1 & 123.2 & 117.1 & 116.4 \\
\hline $4-5-6$ & 119.1 & 119.1 & 118.4 & 118.6 & 123.9 & 124.1 \\
\hline $5-6-1$ & 119.0 & 119.4 & 119.5 & 119.5 & 119.1 & 119.5 \\
\hline $6-1-2$ & 121.5 & 121.3 & 116.7 & 116.6 & 116.9 & 116.6 \\
\hline $6-1-7$ & 121.7 & 122.1 & 122.1 & 122.1 & 121.6 & 121.7 \\
\hline $1-7-8$ & 121.5 & 122.0 & 120.7 & 120.9 & 120.7 & 120.8 \\
\hline 7-8-9 & 120.8 & 120.9 & 120.8 & 120.9 & 120.7 & 120.9 \\
\hline $8-9-10$ & 120.1 & 120.2 & 120.2 & 120.2 & 120.2 & 120.2 \\
\hline $9-10-11$ & 119.6 & 119.5 & 119.5 & 119.5 & 119.6 & 119.6 \\
\hline $10-11-12$ & 120.3 & 120.4 & 120.2 & 120.3 & 120.2 & 120.2 \\
\hline $11-12-7$ & 120.6 & 120.8 & 120.8 & 120.8 & 120.7 & 120.8 \\
\hline 12-7-8 & 118.6 & 118.4 & 118.5 & 118.3 & 118.6 & 118.3 \\
\hline $2-1-7-12$ & 29.1 & 20.7 & 45.6 & 38.5 & 43.5 & 36.3 \\
\hline
\end{tabular}

calculations we used the $\mathrm{B} 3 \mathrm{LYP}^{24}$ hybrid exchange-correlation energy functional to represent the exchange and correlation energy potentials. Since it is a well-documented fact that RHF theory at the $6-31 \mathrm{G}^{*}$ level provides equilibrium geometries which are in very good agreement with experiment, our option of obtaining the equilibrium geometries through the use of two different calculation procedures aimed to assess if the differences between the DFT/B3LYP and the RHF/6-31G* equilibrium geometries are small enough to support the choice of the least expensive RHF/6-31G* method.

The optimum geometries obtained by the two methods are shown in Table 5. In each molecule the bond between the two rings links the carbon atom number 1 in the pyridine ring to the carbon atom number 7 in the phenyl ring, so the nitrogen atom in 2-phenylpyridine has the number 2, in 3-phenylpyridine it is the number 3, and in 4- phenylpyridine it is the number 4. For the sake of conciseness, we omitted the geometrical parameters relative to the hydrogen atoms. As can be seen from that table, the results from both methods are consistent with each other and very similar. The B3LYP calculations predict systematically larger bond lengths but the differences are, however, very small and lie in the range $0.01-0.02 \AA$, with the largest differences occurring for the $\mathrm{C}-\mathrm{N}$ bonds. Similarly, the bond angles are predicted by both methods with deviations from each other not exceeding $0.5^{\circ}$, the largest deviation occurring when the central atom is the most electronegative nitrogen atom. Large deviations of about $7^{\circ}-9^{\circ}$ are however obtained for the inter-ring twisting angles. This is a critical parameter which is determined by the delicate balance of several interactions between the atoms constituting the two rings: on one hand there are the repulsions between the (ortho) hydrogen atoms of different rings, which tend to maintain them in orientations close to mutual perpendicularity. On the other hand, the possibility of a stabilizing interaction between the $\pi$ electronic clouds of the two rings, leading to extended electronic delocalization across the rings, is clearly favored by the planar 
TABLE 6: Calculated Energies (in hartrees)

\begin{tabular}{lllll}
\hline & B3LYP/6-31G* & B3LYP/6-31G** & BP88 \\
\hline biphenyl & -463.30597526 & -463.32183594 & -463.45978940 \\
2-phenylpyridine & -479.34526968 & -479.35938891 & -479.50778780 \\
3-phenylpyridine & -479.34241873 & -479.35637505 & -479.50450753 \\
4-phenylpyridine & -479.34299771 & -479.35695711 & -479.50526699
\end{tabular}

conformation of the molecules. This extended electronic delocalization manifests itself in the values of the inter-ring $\mathrm{C}-\mathrm{C}$ bond $(1-7)$ through which it occurs. As can be seen from Table 5 , this bond has a length which lies between that of a pure single bond (ca. $1.53 \AA$ ) and that of a pure double bond (ca. $1.33 \AA$ ). The resulting balance between these opposing properties determines the equilibrium value of the inter-ring twisting angle. Both calculational methods predict nonplanar conformations for all phenylpyridines, which are consistent with the properties mentioned above even though the results show some variations. Thus, the RHF calculations predicted the inter-ring twist angle to be $27.9^{\circ}$ (2-PhPy), $45.6^{\circ}$ (3-PhPy), and $43.5^{\circ}$ (4-PhPy), while the corresponding predictions of DFT are $20.7^{\circ}$ (2-PhPy), $37.9^{\circ}$ (3-PhPy), and $36.0^{\circ}$ (4-PhPy). The accuracy of the above results can be assessed from the estimated inter-ring twist angles and bond lengths of $\left(45.5^{\circ}, 1.491 \AA\right)$ and $\left(39.3^{\circ}, 1.485 \AA\right)$ obtained in this work for the biphenyl molecule with RHF and DFT/ B3LYP methods, respectively. These figures compare very well with the experimental gas-phase values of $44.1^{\circ} \pm 1.2^{\circ}$ and $1.507 \pm 0.004 \AA$, obtained from electron diffraction measurements, ${ }^{25}$ even though DFT calculations seem to overestimate slightly the $\pi$ electron delocalization across the two rings, thus leading to smaller bond lengths and twist angles. We can thus conclude that both methods of calculation give reliable predictions of the equilibrium geometries of the molecules studied and the equilibrium geometries obtained with the RHF method can be safely accepted.

However, noncorrelated RHF results are of course useless when one tries to accurately describe reaction energetics; for that purpose the DFT results must be used. In addition to the mentioned DFT calculations, we also calculated the energies of the phenylpyridines using DFT/B3LYP with the 6-31G** basis $\operatorname{set}^{23}$ and DFT calculations together with the Becke nonlocal exchange functional ${ }^{26}$ and the Perdew nonlocal correlation functional. ${ }^{27}$ In the last calculations, denoted BP88 in the Tables 6 and 7, we used a double-zeta quality basis set, including polarization functions on first-row atoms, which has been properly optimized for DFT calculations. In this basis set, usually denoted DZVP2, the $\mathrm{H}$ atoms have a (41) contraction pattern (using Huzinaga notation ${ }^{28}$ ) whereas the first-row atoms have a (721/51/1) contraction pattern. It is thus roughly equivalent in size to the conventional Pople 6-31G* basis set. In all B3LYP calculations the molecules were considered at their most stable B3LYP/6-31G* geometries, while for the BP88 calculations we adopted their equilibrium RHF/6-31G* geometries. All RHF and B3LYP calculations were performed using the UK version of program GAMESS ${ }^{29,30}$ while the DFT/BP88 calculations were performed using an academic version of the
deMon program. ${ }^{31,32}$ The results of all calculations are collected in Table 6, where we also included, for comparison purposes, the energy of biphenyl obtained from analogous calculations.

In addition, estimates of the Hessian matrices were obtained for all phenylpyridine isomers, using RHF calculations and the 3-21G basis set. ${ }^{33}$ These force constant matrices provide the information needed to correct for the temperature effects on the reaction energies obtained at $T=0 \mathrm{~K}$. The reason for the choice of this basis set was dictated by the need to avoid the enormous amount of CPU time required for the same calculations with the more complete $6-31 G^{*}$ basis set and by the well-known fact that vibrational frequencies estimated from the two basis sets uniformly overestimate experimental ones by about $10 \%$. The resulting vibrational frequencies were thus scaled by the factor 0.9 .

The relative stability of the phenylpyridines can be assessed through the energy (or enthalpy) variation of the reactions

$$
\begin{aligned}
& \mathrm{C}_{11} \mathrm{H}_{9} \mathrm{~N}+13 \mathrm{CH}_{4}+\mathrm{NH}_{3} \rightarrow \\
& 5 \mathrm{CH}_{2} \mathrm{CH}_{2}+6 \mathrm{CH}_{3} \mathrm{CH}_{3}+\mathrm{CH}_{2} \mathrm{NH}+\mathrm{CH}_{3} \mathrm{NH}_{2}
\end{aligned}
$$

which are likely to produce a substantial cancellation of the correlation errors introduced in the calculations, since they are of the isodesmic type. On the other hand, the use of such reactions provides estimates of the stabilizing effect of electronic delocalization and, since the auxiliary simple molecules are well studied experimentally, we will be also able to estimate the enthalpies of formation of the phenylpyridines.

The corresponding bond separation reaction for biphenyl is

$$
\mathrm{C}_{12} \mathrm{H}_{10}+14 \mathrm{CH}_{4} \rightarrow 6 \mathrm{CH}_{2} \mathrm{CH}_{2}+7 \mathrm{CH}_{3} \mathrm{CH}_{3}
$$

The energies of all auxiliary molecules have also been obtained using the same calculation procedures described for phenylpyridynes. The resulting reaction energies at $T=0 \mathrm{~K}$ and enthalpies at $T=298 \mathrm{~K}$ are presented in Table 7, together with the corresponding experimental estimates. We can see from the results in this table that, with the exception of biphenyl, the energetics of the bond separation reactions are fairly well reproduced by all the calculation methods, the better results being those obtained from B3LYP/6-31G** calculations, which are in error by at most $15 \mathrm{~kJ} \mathrm{~mol}^{-1}$. This fact means that this calculation method is able to predict the enthalpies of formation of phenylpyridines as $-237.2,-255.8$, and $-255.1 \mathrm{~kJ} \cdot \mathrm{mol}^{-1}$, respectively, for 2-phenylpyridine, 3-phenylpyridine, and 4-phenylpyridine. This with errors which are not larger than $15 \mathrm{~kJ}$ $\mathrm{mol}^{-1}$. On the other hand, biphenyl represents the worst case studied, since all calculation methods predict the energetics of its bond separation reaction with large errors of about $40 \mathrm{~kJ}$ $\mathrm{mol}^{-1}$. These large errors are unlikely solely the result of the calculations. A portion of the error can be traced back to the weakness of using bond separation reactions involving a great number of molecules, thus amplifying the individual errors either in the calculated energies or in the experimental formation

\begin{tabular}{|c|c|c|c|c|c|c|c|}
\hline & \multicolumn{2}{|c|}{ B3LYP/6-31G* } & \multicolumn{2}{|c|}{ B3LYP/6-31G** } & \multicolumn{2}{|c|}{ B88 } & \multirow{2}{*}{$\begin{array}{c}\exp ^{a} \\
\Delta H_{298 \mathrm{~K}}\end{array}$} \\
\hline & $\overline{\Delta E_{0 \mathrm{~K}}}$ & $\overline{\Delta H_{298 \mathrm{~K}}}$ & $\Delta E_{0 \mathrm{~K}}$ & $\overline{\Delta H_{298 \mathrm{~K}}}$ & $\overline{\Delta E_{0 \mathrm{~K}}}$ & $\overline{\Delta H_{298 \mathrm{~K}}}$ & \\
\hline biphenyl & 592.3 & 630.3 & 587.9 & 626.0 & 591.5 & 629.5 & 588.8 \\
\hline 2-phenylpyridine & 608.9 & 646.1 & 605.6 & 642.8 & 613.6 & 650.8 & 633.9 \\
\hline 3-phenylpyridine & 601.4 & 639.2 & 597.6 & 635.5 & 605.0 & 642.8 & 620.6 \\
\hline 4-phenylpyridine & 602.9 & 640.4 & 599.2 & 636.6 & 607.0 & 644.4 & 621.5 \\
\hline
\end{tabular}
enthalpies. Thus, if, instead of the bond separation reaction for

TABLE 7: Calculated Reaction Energies and Enthalpies (in kJ·mol ${ }^{-1}$ )

${ }^{a}$ The values of the standard molar enthalpies of formation of the compounds involved on these calculations were taken from refs 34 and 36 . 
biphenyl, we consider the following reaction

$$
\mathrm{C}_{12} \mathrm{H}_{10}+\mathrm{C}_{5} \mathrm{H}_{5} \mathrm{~N} \rightarrow \mathrm{C}_{11} \mathrm{H}_{9} \mathrm{~N}+\mathrm{C}_{6} \mathrm{H}_{6}
$$

we will obtain the following values for the enthalpy of formation for biphenyl: $180.8,186.8$, and $187.0 \mathrm{~kJ} \mathrm{~mol}^{-1}$, respectively, from the measured enthalpy of formation of 2-phenylpyridine, 3-phenylpyridine, and 4-phenylpyridine, and the calculated B3LYP/6-31G** energies. These results are in very good agreement with the experimental value of $182.0 \pm 0.7 \mathrm{~kJ} \mathrm{~mol}^{-1}$ for the enthalpy of formation of biphenyl. ${ }^{34}$

As we have seen earlier in Table 5, the inter-ring $\mathrm{C}-\mathrm{C}$ bond $(1-7)$ of the phenylpyridines seem to have a very similar percentage of double bond character for all isomers, a result that follows from the almost constant bond length predicted from our geometry optimizations. This suggests that these bonds should also have the same intrinsic strength for all isomers. The strength of this bond has been calculated from the DFT/B3LYP results as the energy variation of the dissociation reactions of the phenylpyridines and biphenyl. The bond dissociation energies (at $T=0 \mathrm{~K}$ ) obtained with the $6-31 \mathrm{G}^{* *}$ basis set were 480.0 , 466.1, 482.8, and $479.4 \mathrm{~kJ} \mathrm{~mol}^{-1}$ for biphenyl, and 2-, 3-, and 4-phenylpyridine, respectively. The corresponding experimental bond dissociation enthalpy at $T=298 \mathrm{~K}$ for biphenyl is $496.0 \mathrm{~kJ} \cdot \mathrm{mol}^{-1}$, in good agreement with the above value. The bond dissociation energy predicted for the 3- and 4-isomers of phenylpyridine are very similar to that predicted for biphenyl, a fact which is consistent with the nearly constant double-bond character of the $\mathrm{C}-\mathrm{C}$ inter-ring bonds observed for all molecules studied. However, for 2-phenylpyridine we predict a bond dissociation energy which is lower by about 14 $\mathrm{kJ} \cdot \mathrm{mol}^{-1}$ relative to the other isomers, in contrast with the observed and the predicted stability order of phenylpyridines. The main reason for this lowering of the bond dissociation energy is a corresponding higher stabilization of the 2-pyridyl radical relative to the other isomeric radicals, which is a result of a favorable interaction between the nitrogen lone electronic pair and the unpaired electron at the neighboring carbon atom, when this is located at the ortho position. The occurrence of such a stabilizing interaction can be evidenced by a natural bond orbital (NBO) analysis ${ }^{35}$ of the RHF/6-31G* molecular orbitals. In this way we observed that, in 2-phenylpyridine, the natural localized molecular orbital (NLMO) representing the lone pair of electrons on nitrogen shows a considerable contribution of $0.7 \%$ from the hybrid orbital representing the lone electron on the carbon atom. This is in fact the second largest contribution to that localized orbital. The corresponding contributions for 3 - and 4-phenylpyridine are $0.3 \%$ and $0.02 \%$, respectively. Thus, the lowering of the bond dissociation energy of 2-phenylpyridine is mainly the result of a higher stability of the corresponding pyridyl radical, instead of being associated with a greater instability of the molecule.

Acknowledgment. Thanks are due to Fundação para a Ciência e Tecnologia (FCT) for financial support to the Faculty of Science of the University of Porto projects PRAXIS XXI/ PCEX/QUI/62/96, as well as to Centro de Investigação em Química da Universidade do Porto (Research Unit number 81, L.5). C.A.R. thanks JNICT for the award of a research grant under PRAXIS XXI (research grant BM/2003/94).

\section{References and Notes}

(1) (a) Ribeiro da Silva, M. A. V.; Morais, V. M. F.; Matos, M. A. R.; Rio, M. C. A. J. Org. Chem. 1995, 60, 5291. (b) Ribeiro da Silva, M. A. V.; Morais, V. M. F.; Matos, M. A. R.; Rio, M. C. A.; Piedade, C. M. G. S. Structural Chemistry 1996, 7, 329. (c) Ribeiro da Silva, M. A. V.; Matos, M. A. R. Pure Appl. Chem. 1997, 69, 2295.

(2) Handbook of Chemistry and Physics, 70th ed.; Weast, R. C., Ed.; CRC Press Inc.: Cleveland, OH 1989-1990.

(3) Ribeiro da Silva, M. A. V.; Ribeiro da Silva, M. D. M. C.; Pilcher, G. Rev. Port. Quim. 1984, 26, 163 .

(4) Ribeiro da Silva, M. A. V.; Ribeiro da Silva, M. D. M. C.; Pilcher, G. J. Chem. Thermodyn. 1984, 16, 1149 .

(5) Coops, J.; Jessup, R. S.; Van Nes, K. In Experimental Thermochemistry; Rossini, F. D., Ed.; Interscience: New York, 1956; Vol. 1, Chapter 3.

(6) The NBS Tables of Chemical Thermodynamic Properties. J. Phys. Chem. Ref. Data 1982.

(7) Skinner, H. A.; Snelson, A. Trans. Faraday Soc. 1960, 56, 1776.

(8) Hubbard, W. N.; Scott, D. W.; Waddington, G. In Experimental Thermochemistry; Rossini, F. D., Ed.; Interscience: New York, 1956; Vol. 1, Chapter 5.

(9) I.U.P.A.C. J. Phys. Chem. Ref. Data 1997, 26, 1239.

(10) Sabbah, R.; Xu-wu, A.; Chickos, J. S.; Planas Leitão, M. L.; Roux, M. V.; Torres, L. A. Thermochim. Acta 1999, 331, 93.

(11) Chickos, J. S.; Hesse, D.; Hosseini, S.; Nichols, G.; Webb, P. Thermochim. Acta 1998, 313, 101

(12) Malanowski, S. Bull. Acad. Polon. Sci. Ser. Sci. Chim. 1961, 9 , 71

(13) Coulson, E. A.; Cox, J. D.; Herington, E. F. G.; Martin, J, F. J Chem. Soc. 1959, 1934

(14) Malonowska, B.; Wecsile, J. Bull. Acad. Pol. Sci. 1964, 12, 239

(15) Camin D. L.; Rossini F. D. J. Phys. Chem. 1955, 59, 1173

(16) Stephenson, R. M.; Malonowski, S. Handbook of the Thermodynamics of Organic Compounds; Elsevier: New York, 1987.

(17) Chickos, J. S.; Hesse, D. G.; Liebman, J. F. Struct. Chem. 1993, 4, 261.

(18) Adedeji F. A.; Brown D. L. S.; Connor J. A.; Leung, M.; PazAndrade M. I.; Skinner H. A. J. Organomet. Chem. 1975, 97, 221.

(19) Stull, D. R.; Westrum E. F.; Sinke G. C. The Chemical Thermodynamics of Organic Compounds; Wiley: New York, 1969.

(20) Ribeiro da Silva, M. A. V.; Matos, M. A. R.; Amaral, L. M. P. F. J. Chem. Thermodyn. 1995, 27, 565.

(21) Rossini, F. D. In Experimental Thermochemistry; Rossini, F. D., Ed.; Interscience: New York, 1956; Vol. 1, Chapter 14, pp 297-320.

(22) J. Chem. Thermodyn. 1978, 10, 903.

(23) Hariharan, P. C.; Pople, J. A. Chem. Phys. Lett. 1972, 66, 217

(24) Becke, A. D. J. Chem. Phys. 1993, 98, 5648

(25) Almeningen, A.; Bastiansen, O.; Fernholt, L.; Cyvin, B. N.; Cyvin, S. J.; Sandal, S. J. Mol. Struct. 1985, 128, 59.

(26) Becke, A. D. Phys. Rev. 1988, A38, 3098.

(27) Perdew, J. P. Phys. Rev. 1986, B33, 8822

(28) Huzinaga, S., Ed. Gaussian Basis Sets for Molecular Calculations; Elsevier: New York, 1984.

(29) UK-GAMESS is a package of ab initio programs written by: Guest, M. F. J. H.; van Lenthe, M. F.; Kendrick, J.; Schoffel, K.; Sherwood, P., with contributions from: Amos, R. D.; Buenker, R. J.; van Dam, H. J. J.; Dupuis, M.; Handy, N. C.; Hillier, I. H.; Knowles, P. J.; Bonacic-Koutecky, V.; von Niessen, W.; Harrison, R. J.; Rendell, A. P.; Saunders: V. R.; Stone, A. J. and de Vries, A. H. The package is derived from the original GAMESS code due to: Dupuis, M.; Spangler, D.; Wendoloski, J. NRCC Software Catalog, Vol. 1, Program No. QG01 (GAMESS), 1980.

(30) The DFT module within GAMESS-UK was developed by Dr. P. Young under the auspices of EPSRC's Collaborative Computational Project No. 1 (CCP1) 1995-1997.

(31) St-Amant, A.; Salahub, D. R. Chem. Phys. Lett. 1990, 169, 387

(32) St-Amant, A. Ph.D. Thesis, Université de Montréal, 1992.

(33) Binkley, J. S.; Pople, J. A.; Hehre, W. J. Am. Chem. Soc. 1980, 102, 939 .

(34) Pedley, J. B. Thermochemical Data and Structures of Organic Compounds; TRC Data Series; Texas A\&M University: College Station, TX, 1994; Vol. I.

(35) Reed, A. E.; Curtiss, L. A.; Weinhold, F. Chem. Rev. 1988, 88, 899.

(36) Defrees, D. J.; Hehre, W. J. J. Phys. Chem. 1978, 82, 391. 